\section{Detection of Pigments and Natural Colorants from Thai Herbal Plants for Possible Use as Coloring Dyes}

\author{
Panthip Boonsong, Natta Laohakunjit, and Orapin Kerdchoechuen \\ School of Bioresources and Technology, King Mongkut's University of \\ Technology Thonburi, Bangkok, Thailand 10150
}

\author{
Frank B. Matta ${ }^{1}$ \\ Department of Plant and Soil Sciences, P.O. Box 9555, Mississippi State \\ University, Mississippi State, MS 39762
}

Additional index words. solvent extraction, polyphenols, absorption spectra, high-performance liquid chromatography

\begin{abstract}
Fourteen Thai herbal plants were extracted using methanol, ethanol, and acetone. Comparison of the various extraction methods for pigments and polyphenols (colorants) showed that methanol provided a more complete extraction than ethanol and acetone. Percentage yield ranged from 1.7 to 40.7 and was dependent on the plant extracted and solubility of pigments and polyphenols (colorants) extracted by the various solvents. The absorption spectra of pigments and polyphenols (colorants) in the plant extract were present in the visible region $(351$ to $665 \mathrm{~nm})$ and the absorption spectra of polyphenols were present in the ultraviolet region $(200$ to $349 \mathrm{~nm})$. Color of plant extracts varied and included violet-blue, yellow-green, red, orange-red, gray-purple, bluegreen, gray-orange, gray-yellow, and black. High-performance liquid chromatography (HPLC) was used to separate and identify compounds of plant pigments and polyphenols (colorants). Ya-nang had the greatest number of peaks and chlorophyll A and chlorophyll $B$ were found only in Ya-nang. Numerous pigments and polyphenols were detected. Such compounds have the potential to be used as coloring dyes.
\end{abstract}

Synthetic hair coloring products are widely used and are known to cause problems such as breakage of hair stands, loss of hair, dry scalp, risk of cancer (Zheng et al., 2002), allergic, and mutagenic and carcinogenic effects (Thun et al., 1994). Compounds considered harmful include 4-methoxy m-phenylenediamine (4MMPD) or 4-methoxy-m-phenylenediamine sulfate (4MMPD sulfate), two coal-tar ingredients (Hecht, 1978). Currently, there is a popular trend in using pigments and colorants from plant extracts as substitutes for synthetic colorants, because natural pigments and colorants are non-toxic and non-mutagenic, have desirable pharmacological properties (Lazzé et al., 2003), and are friendly to the environment. The horticulture industry in countries such as Thailand that have an abundance of herbal plants may benefit economically from culturing and marketing such plants for the extraction of plant pigments and colorants for use in the production of coloring products. The main pigment compounds of plants are carotene (golden), pheophytin (olive green), chlorophyll a (blue-green), chlorophyll b (yellow-green), lutein (yellow), xanthophylls (yellow), betalains (yellow, orange, red, purple), and anthocyanins (red). In addition, polyphenols such as tannins, flavonoids,

Received for publication 24 Aug. 2010. Accepted for publication 10 Dec. 2010.

${ }^{1}$ To whom reprint requests should be addressed; e-mailfmatta@pss.msstate.edu. and anthocyanins are major plant secondary metabolites and represent the most studied phytochemicals. Harnafi and Amrani (2008) presented a simple technique to determine plant extracts such as polyphenols and used spectrophotometric assays to measure antioxidants. Plant extracts were mainly polynuclear compounds: polyphenols, tannins, flavonols and flavonols-catechin, taxopholin, and quercetin. Panayotov et al. (2006) reported that the quantities of flavonols (large group of yellow-pigmenting polyphenol compounds) contained in extracts of oak (Quercus robur), chestnut (Castanea sativa), mulberry (Morus alba), acacia (Robinia pseudoacacia), teak (Tectona grandis), tany (Tanacetum vulgare), and common rue (Ruta graveolens) were determined with ultraviolet spectrophotometry. Solovchenko et al. (2001) studied pigment extraction of apple peel using polar organic solvents (acetone or methanol) and a chloroform-methanol mixture and found that polar organic solvent extraction did not result in complete extraction of intact pigments. Such extracts contained amounts of light-absorbing impurities. The chloroformmethanol extraction, however, reduced the content of such impurities and increased the accuracy of the content of chlorophylls and carotenoids. In addition, the chloroformmethanol extraction method proved useful for the analysis of phenolic substances (anthocyanins and flavonoids) in the watermethanol fraction of the extracts. Although laboratory equipment and methods exist to identify pigments and polyphenols (colorants) in plants, a limited amount of research has been conducted using herbal plants.

The objective of this study was to detect the presence of pigments and polyphenols (colorants) in herbal plants using ultravioletvisible spectrophotometry and HPLC. This research will provide information on the presence, color, and number of pigments and polyphenols (colorants) in plant extracts for possible use as hair coloring dyes.

\section{Materials and Methods}

Chemicals used for extraction. Chemicals used for extraction of various compounds were organic solvents of analytical grade (acetone, methanol, and ethanol) from Sigma Chemicals (NJ). Silica gel 60 (70 to 230 mesh ASTM) from Merck (Germany) was used for separation by column chromatography. Chlorophyll A, and chlorophyll B standards from Sigma (Switzerland) (purities greater than 98\%) were used to compare with plant extracts by HPLC analysis. Distilled and deionized water was used throughout this study.

Plants used in the study. The following 14 Thai herbal plants were used; butterfly pea (Clitoria ternatea L.), turmeric (Curcuma longa L.), krachaidum (Kaempferia parviflora Wall. ex Baker), kae-lae [Maclura cochinchinensis (Lour.) Corner.], pradu (Pterocarpus macrocarpus Kurz), black rice (Oryza sativa L.), safflower (Carthamus tinctorius L.), ebony tree (Diospyros mollis Griff.), marigold (Tagetes erecta L.), sappan wood (Caesalpinia sappan L.), samor-pipek (Terminalia Belerica Roxb.), roselle (Hibiscus sabdariffa L.), Ya-nang [Tiliacora triandra (Colebr.) Diels], and dragon fruit (Hylocereus undatus L.). Plants were purchased from a local retail shop in Bangkok, Thailand. Before analysis, the plants were washed and dried by hot air oven at $50{ }^{\circ} \mathrm{C}$ for $24 \mathrm{~h}$ and stored dry at $25^{\circ} \mathrm{C}$.

Analysis of extracts. A rotary evaporator (Büchi Rotavapor R200; Büchi Labortechnik AG, Switzerland) was used for solvent removal. An ultraviolet-visible spectrophotometer (ultraviolet-1601; Shimadzu Corporation, Japan) was used for analyzing spectral properties of pigments and polyphenols (colorants). Royal Horticultural Society (RHS) Color Charts (The Royal Horticultural Society, London, UK) was used for measuring color of plant extracts. HPLC (1200 Series; Agilent Technologies) was used for localization and characterization of plant extract.

Pigment extraction. For pigment extraction, $100 \mathrm{~g}$ of plant material was ground in a blender and held at room temperature for maximum color development. Plant material was macerated with $400 \mathrm{~mL}$ of $100 \%$ solvents (acetone, methanol, and ethanol) and placed at room temperature for $1 \mathrm{~d}$. Solvents were then removed and extraction was repeated once with fresh solvents $(400 \mathrm{~mL})$ under the same conditions as described previously. The pigment solution was separated from plant tissue using a Buchner funnel with Whatman No. 1 filter paper. To achieve complete pigment extraction from the plant 
material, the filtered residue was rinsed twice with the extraction solution. The combined extracts were filtered and solvent removed with a rotary evaporator (Büchi Rotavapor R200; Büchi Labortechnik AG). Fats and wax were removed with petroleum ether. All extracts were kept at $4{ }^{\circ} \mathrm{C}$ after preparation until analysis. A yield percentage of plant extract product was calculated by:

$$
\begin{aligned}
\% & \text { yield }(\mathrm{v} / \mathrm{w}) \\
= & \frac{\text { volume of plant extracts }(\mathrm{ml})}{\text { weight of raw materials }(\mathrm{g})} \times 100 \%
\end{aligned}
$$

Statistical analysis. A randomized complete block design with three replications was used for statistical analysis using SAS (SAS Institute, Cary, NC). Extraction yield percentage data were transformed using arcsine. Extraction yield means were separated by Duncan's multiple range test at $P=0.05$.

Identification of pigments and colorants. Plant extracts were placed into a quartz cuvette for spectral measurement. The ultraviolet-visible spectrophotometer (ultraviolet1601; Shimadzu Corporation) was used to analyze by spectrum mode (scanning visible range, $350 \mathrm{~nm}$ to $800 \mathrm{~nm}$; range, $-3.99 \mathrm{~A}$ to 3.99A). Color of plant extract was measured using the RHS Color Charts. HPLC conditions were as follows: methanolic extracts $(10 \mu \mathrm{L})$ were used to identify pigments and colorants by HPLC (1200 Series; Agilent Technologies) with an Eclipse XDB-C18 column $(4.6 \mathrm{~mm}$ i.d. $\times 250 \mathrm{~mm}, 5 \mu \mathrm{m})$. Water and methanol (HPLC-grade) were used in the solvent system. The column was eluted with a mixture of water-methanol (1:1) for $15 \mathrm{~min}$ and then for $50 \mathrm{~min}$ with a linear gradient of methanol-water (1:1) to $100 \%$ methanol. The flow rate was $1 \mathrm{~mL} / \mathrm{min}$ and a variable wavelength diode array detector set at 445 $\mathrm{nm}$; column temperature was $25^{\circ} \mathrm{C}$.

The solvent extracted pigments were separated using column chromatography for a brief study of plant extract compounds using the wavelength of maximum absorption $\left(\lambda_{\max }\right)$. Silica gel 60 (70 to 230 mesh

Table 1. The effects of different solvents on extraction yield, wavelength of maximum absorption, and color in the visible region of the light spectrum of 14 Thai

\begin{tabular}{|c|c|c|c|c|}
\hline Plants & Solvents & Percent yield & $\lambda_{\max }(\mathrm{nm})$ & Color \\
\hline \multirow[t]{3}{*}{ Black rice (Oryza sativa L.) } & Acetone & 5.4 qrs $^{\mathrm{z}}$ & 665 & Gray 201B \\
\hline & Methanol & $6.0 \mathrm{qp}$ & $370,400,420,445,485,510,535,545,570$ & Violet-blue $97 \mathrm{~A}$ \\
\hline & Ethanol & 4.6 tu & 545 & Blue 98B \\
\hline \multirow[t]{3}{*}{ Butterfly pea (Clitoria ternatea L.) } & Acetone & $11.0 \mathrm{ij}$ & 365,570 & Yellow-green $148 \mathrm{C}$ \\
\hline & Methanol & $21.5 \mathrm{c}$ & 360,585 & Yellow-green 147B \\
\hline & Ethanol & 6.8 no & 365,585 & Yellow-green 148D \\
\hline \multirow[t]{3}{*}{ Dragon fruit (Hylocereus undatus L.) } & Acetone & $4.1 \mathrm{u}$ & $350,465,535$ & Red 53C \\
\hline & Methanol & $4.1 \mathrm{u}$ & $355,470,535$ & Red 51B \\
\hline & Ethanol & $7.7 \mathrm{~m}$ & $375,490,540$ & Red 42D \\
\hline \multirow[t]{3}{*}{ Ebony tree (Diospyros mollis Griff.) } & Acetone & $7.7 \mathrm{~m}$ & 365 & Gray-orange 176A \\
\hline & Methanol & $4.9 \mathrm{st}$ & 355 & Gray-orange 166A \\
\hline & Ethanol & $3.3 \mathrm{v}$ & 355 & Gray-orange 166A \\
\hline \multirow{3}{*}{$\begin{array}{l}\text { Kae-lae [Maclura cochinchinensis } \\
\quad \text { (Lour.) Corner.] }\end{array}$} & Acetone & $2.5 \mathrm{w}$ & 380 & Gray-orange 166D \\
\hline & Methanol & 6.5 nop & 370,390 & Gray-orange 173A \\
\hline & Ethanol & $1.7 \mathrm{x}$ & 385 & Gray-red 178A \\
\hline \multirow{3}{*}{$\begin{array}{l}\text { Krachaidum (Kaempferia parviflora } \\
\text { Wall. ex Baker) }\end{array}$} & Acetone & $9.3 \mathrm{k}$ & $360,380,390,405$ & Gray-orange $165 \mathrm{~B}$ \\
\hline & Methanol & $13.3 \mathrm{~h}$ & $360,375,390,425$ & Violet-blue 89D \\
\hline & Ethanol & 5.9 qp & $360,370,380,390,400,420,545$ & Gray-red 180A \\
\hline \multirow[t]{3}{*}{ Marigold (Calendula officinalis L.) } & Acetone & 8.41 & 355 & Yellow-green $147 \mathrm{C}$ \\
\hline & Methanol & 6.4 op & 360 & Gray-yellow 160A \\
\hline & Ethanol & 5.5 qrs & 360 & Gray-orange 167B \\
\hline \multirow[t]{3}{*}{ Pradu (Pterocarpus macrocarpus Kurz) } & Acetone & 8.41 & $360,370,380,420$ & Gray-red 178A \\
\hline & Methanol & $13.4 \mathrm{~h}$ & $360,375,385,420$ & Orange-red $34 \mathrm{~A}$ \\
\hline & Ethanol & $5.5 \mathrm{qr}$ & $360,370,385$ & Gray-red 178A \\
\hline \multirow[t]{3}{*}{ Roselle (Hibiscus sabdariffa L.) } & Acetone & $5.3 \mathrm{rs}$ & $360,605,665$ & Gray-green $188 \mathrm{C}$ \\
\hline & Methanol & $40.7 \mathrm{a}$ & $360,370,390,420,535,665$ & Gray-purple 187A \\
\hline & Ethanol & $14.2 \mathrm{~g}$ & $365,545,665$ & Gray-purple 187B \\
\hline \multirow[t]{3}{*}{ Safflower (Carthamus tinctorius L.) } & Acetone & 6.7 no & 370,510 & Gray-brown 199B \\
\hline & Methanol & $26.3 \mathrm{~b}$ & 370,520 & Gray-orange 166B \\
\hline & Ethanol & $10.7 \mathrm{j}$ & 365,520 & Gray-brown 199C \\
\hline \multirow[t]{3}{*}{ Samor-pipek (Terminalia Belerica Roxb.) } & Acetone & $9.7 \mathrm{k}$ & $365,380,395,420,605,665$ & Gray-brown 199A \\
\hline & Methanol & $20.9 \mathrm{c}$ & $360,380,395,410,425,435,605,665$ & Gray-orange 174D \\
\hline & Ethanol & $11.3 \mathrm{i}$ & $360,390,610,665$ & Yellow-green 153D \\
\hline \multirow[t]{3}{*}{ Sappan wood (Caesalpinia sappan L.) } & Acetone & $5.6 \mathrm{qr}$ & 435 & Gray-orange $176 \mathrm{~A}$ \\
\hline & Methanol & $14.5 \mathrm{~g}$ & 445 & Gray-orange $176 \mathrm{~A}$ \\
\hline & Ethanol & $7.1 \mathrm{mn}$ & 445 & Gray-orange $176 \mathrm{~A}$ \\
\hline \multirow[t]{3}{*}{ Turmeric (Curcuma longa L.) } & Acetone & $16.6 \mathrm{e}$ & $365,380,390,405,420,445,460,485$ & Orange-red 34B \\
\hline & Methanol & $21.4 \mathrm{c}$ & $360,370,380,390,425,445,460,485,520$ & Orange-red 34B \\
\hline & Ethanol & $18.2 \mathrm{~d}$ & $365,375,395,425,450,460,470,485,515$ & Orange-red 34B \\
\hline \multirow[t]{3}{*}{ Ya-nang [Tiliacora triandra (Colebr. Diels)] } & Acetone & $15.5 \mathrm{f}$ & $380,395,405,445,475,505,535,560,610,660,675$ & Black 202A \\
\hline & Methanol & $13.3 \mathrm{~h}$ & $380,405,425,475,505,535,565,615,675$ & Black 202A \\
\hline & Ethanol & $14.2 \mathrm{~g}$ & $365,380,395,425,450,530,555,605,660$ & Black 202A \\
\hline
\end{tabular}
herbal plants.

${ }^{\mathrm{z}}$ Means in column separated by Duncan's multiple range test. Values with different letters are significantly different at the 0.05 level. 
Table 2. Ultraviolet-visible absorption data of fractions from 14 Thai herbal plants.

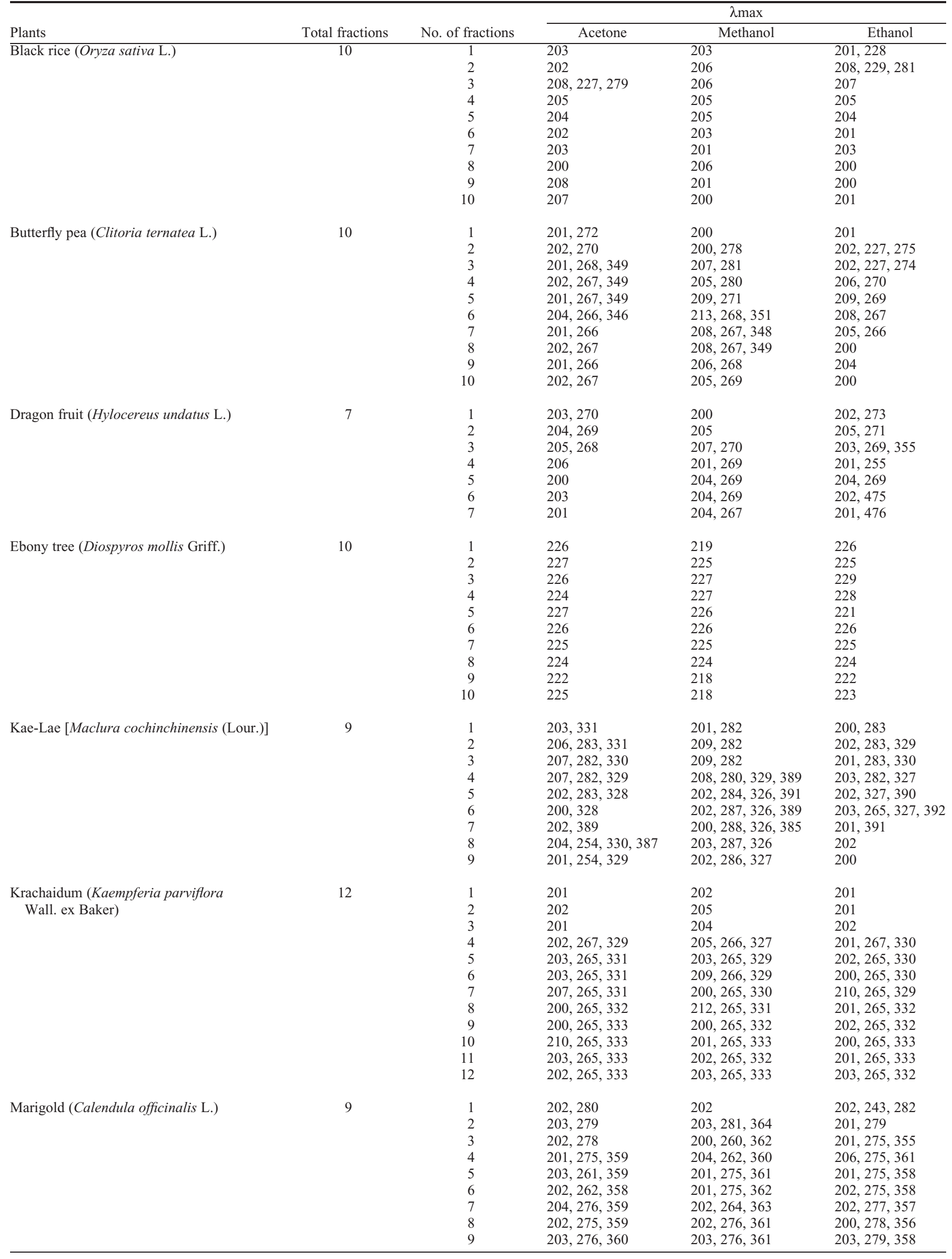


Table 2. (Continued) Ultraviolet-visible absorption data of fractions from 14 Thai herbal plants.

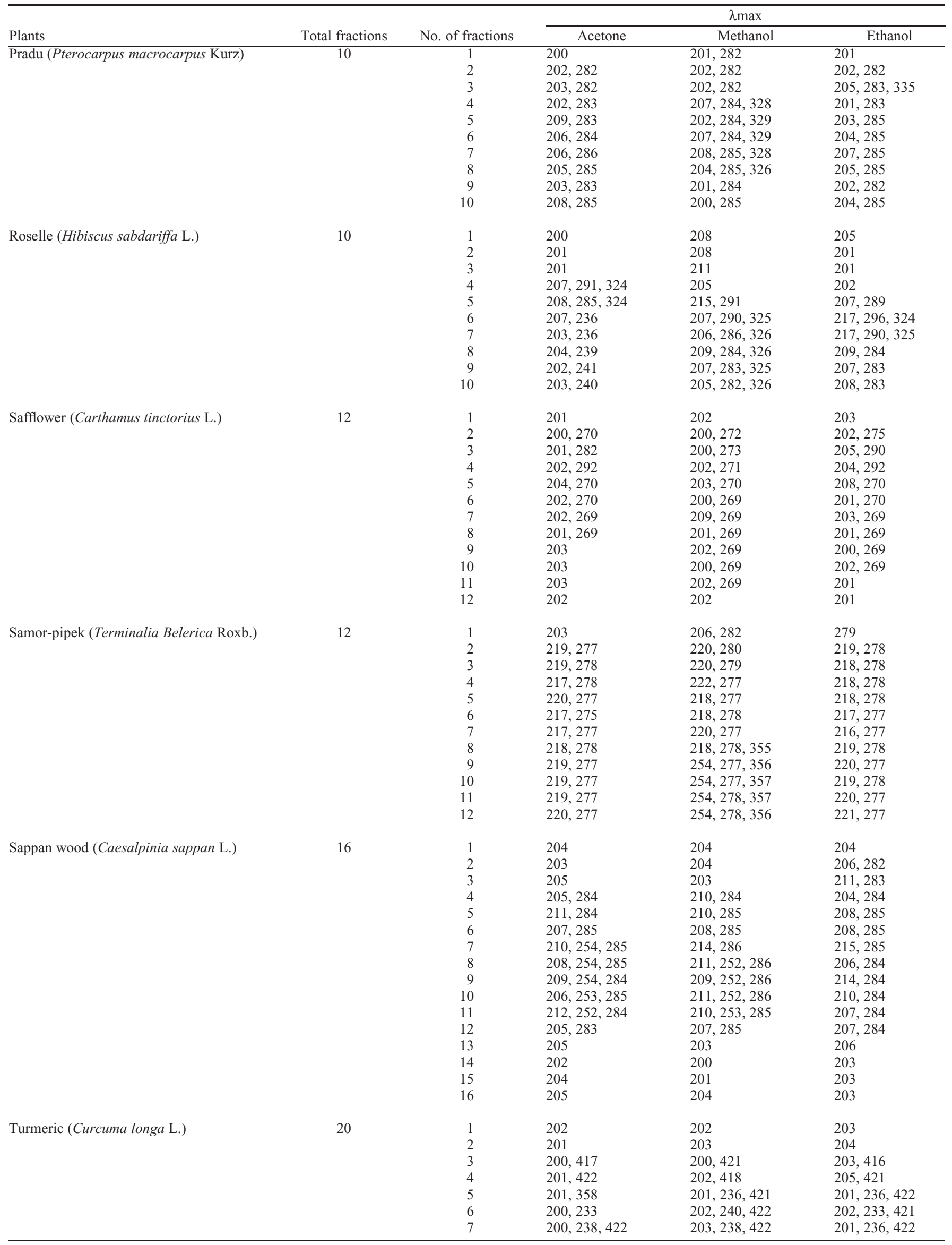

(Continued on next page) 
Table 2. (Continued) Ultraviolet-visible absorption data of fractions from 14 Thai herbal plants.

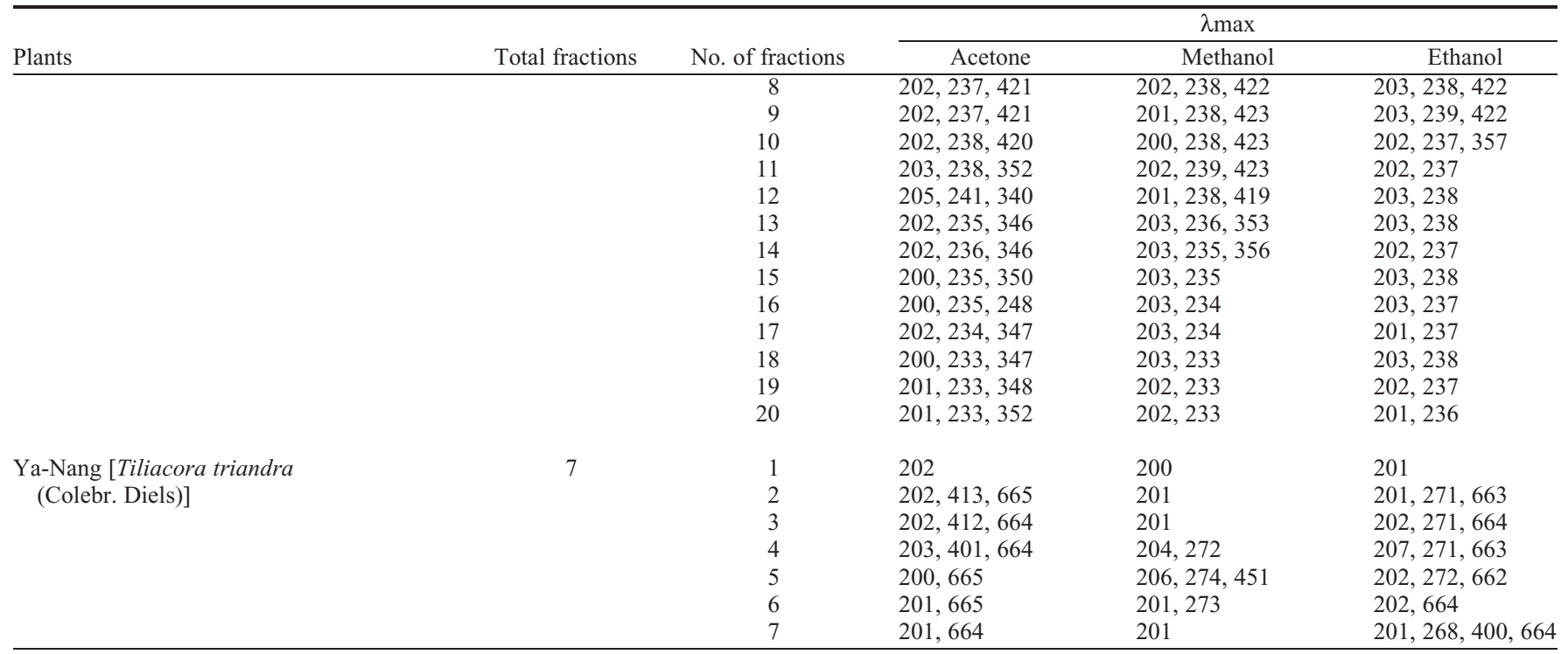

ASTM) $40 \mathrm{~g}$ was slurred in $60 \%$ methanol in water and held $1 \mathrm{~h}$. A glass column $(28 \times 2.5$ $\mathrm{cm}$ i.d.) was filled with silica gel. The sample $(2 \mathrm{~mL})$ was applied to the silica gel and then eluted with $60 \%$ methanol in water at a flow rate of $1 \mathrm{~mL} / \mathrm{min}$. The eluent was allowed to flow down through the column and a total of $5 \mathrm{~mL} /$ fraction was collected for analysis. The fraction was analyzed by ultraviolet-visible spectrophotometer (scanning range, $190 \mathrm{~nm}$ to $800 \mathrm{~nm}$; range, $-3.99 \mathrm{~A}$ to $3.99 \mathrm{~A}$ ).

\section{Results and Discussion}

Pigments extracted with methanol gave the highest percentage yield of pigment and polyphenols (colorants) (Table 1). Examples are roselle with 40.7, safflower with 26.3, butterfly pea with 21.5 , and turmeric with 21.4. Anthocyanins are usually extracted with organic solvent, most commonly methanol. Methanol destroys cell membranes and simultaneously dissolves the anthocyanins (Shahidi and Naczk, 2003). Ethanol extraction gave the highest yield of pigment and polyphenols (colorants) in dragon fruit with 7.7, and acetone extraction gave the highest yield of pigment and polyphenols (colorants) in Ya-nang with 15.5, marigold (Tagetes erecta L.) with 8.4, and ebony tree with 7.7. Overall, results of the solvent extraction can be explained by the relationship between the polarity of solvents and the structure of pigments and polyphenols (colorants); methanolic extraction gave the highest yield because pigments and polyphenol compounds such as flavonoids (anthocyanins, flavonol) and nonflavonoids (phenolic acid) are soluble in methanol. Khanavi et al. (2009) compared the effect of different solvent extraction methods on antioxidant activity and content of total phenolics in Stachys species and reported significant difference among solvents used; methanolic extraction gave the highest antioxidant activity and total phenolic content.
Measuring the absorbance at different wavelengths provides an absorption spectrum for the pigments and colorants in the extracts. Because different pigments and colorants have different absorption spectra, pigments and colorants can be tentatively identified by their absorption spectra (Ross, 1974). In this study, black rice absorbed the wavelengths of violet, blue, green, and yellow, thus reflecting the yellow, orange, red, and violet color. Butterfly pea absorbed the wavelengths of violet and yellow, thus reflecting the yellow and violet color. Dragon fruit absorbed the wavelengths of violet, blue, and green, thus reflecting the yellow, orange, and red color. Ebony tree, kae-lae, marigold, and pradu absorbed the wavelengths of violet, thus reflecting the yellow color. Krachaidum absorbed the wavelengths of violet and green, thus reflecting the yellow and red color. Roselle absorbed the wavelengths of violet, green, orange, and red, thus reflecting the yellow, red, blue, and green color. Safflower absorbed the wavelengths of violet and cyan, thus reflecting the yellow and red-orange color. Samor-pipek absorbed the wavelengths of violet, orange, and red, thus reflecting the yellow, blue, and green color. Sappan wood absorbed the wavelengths of blue, thus reflecting the orange color. Turmeric absorbed the wavelengths of violet, blue, and cyan, thus reflecting the yellow, orange, and red-orange color. Ya-nang absorbed the wavelengths of violet, blue, cyan, green, orange, and red, thus reflecting the yellow, orange, redorange, red, blue, and green color (Table 1). In a previous study, anthocyanins absorb mainly in the green and yellow regions of the spectrum (Karageorgou and Manetas, 2006). Chlorophyll $\mathrm{a}$ and $\mathrm{b}$ can absorb visible light in the red region and blue region (Lee and Schwartz, 2006). Carotenoids absorb light in the violet and blue region of the spectrum (Glimn-Lacy and Kaufman, 2006). Therefore, anthocyanins, chlorophylls, and carotenoids are potentially present in plant extracts analyzed in this study.
Color of the plant extracts is listed in Table 1. Color varied depending on the plants extracted and the solvent used for extraction. Examples are butterfly pea extract (yellowgreen color), dragon fruit extract (red color), pradu extract (gray-red and orange-red color), sappan wood and ebony tree extract (grayorange color), turmeric extract (orange-red color), kae-lae extract (gray-orange and grayred color), roselle extract (gray-green and graypurple color), safflower extract (gray-brown and gray-orange color), and Ya-nang extract (black color). The different colors of plant extract with various solvents may be the result of different physical properties (solubility) and different types of pigments and polyphenols (colorants) in the plants.

Spectrophotometric analysis of the various fractions of each plant extract had similar major absorption peaks at wavelengths in the areas of the ultraviolet region and some fractions also peaked at the visible region (Table 2). Each fraction had a different shade of color; thus, the wavelengths of maximum absorption changed in each fraction. Comparison of the absorption spectra and various absorbance ratios revealed differences in the extract of pigments sampled from different solvents (Tietjen, 1970). The ultraviolet spectrum of the same groups and same derivatives such as flavonol aglycones, anthocyanidin, phenolic acid, and their derivatives have a similar spectrum for each group, which can be used for spectrum analysis for qualitative and selective evaluation of classification of plant phenolics (Maisuthisakul et al., 2005).

In this study, results using HPLC showed that each plant extract had several peaks in the chromatogram, and different peaks (compounds) had different retention times (Fig. 1). Ya-nang had the greatest number of peaks (10) followed by krachaidum with six and ebony tree with five. The remaining herbal plant extracts had one to four peaks depending on the plant. Chlorophyll A and chlorophyll B 

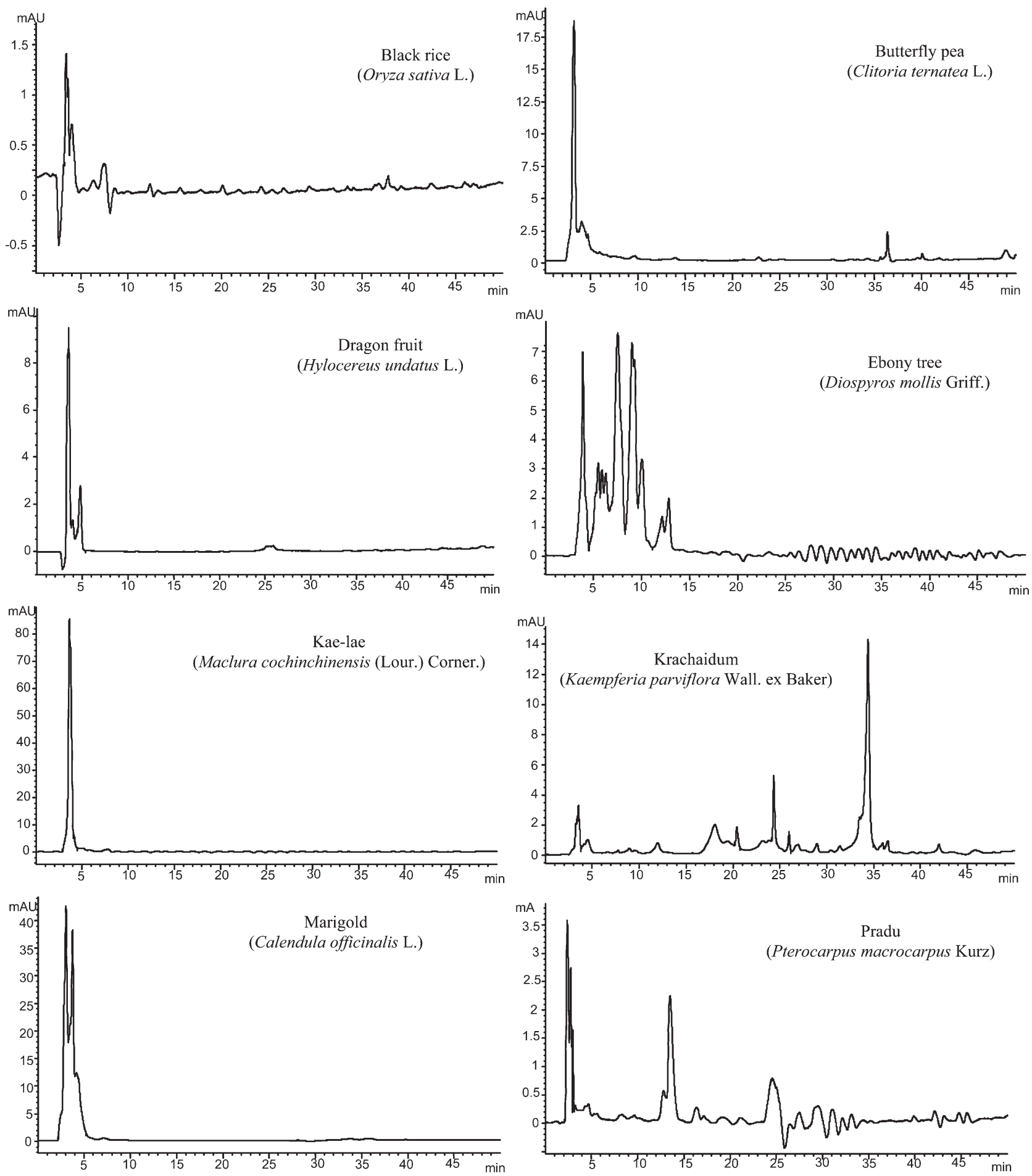

Fig. 1. High-performance liquid chromatograms of pigments isolated from 14 Thai herbal plants showing absorbance in milli absorbance units (mAU) with time in minutes.

were found only in Ya-nang. In a previous study, it was reported that turmeric had phenolic compounds (curcuminoids) as main compounds, which give the yellow color. Curcuminoids contain three different diarylheptanoids, curcumin (diferuloylmrthane), demethoxycurcumin ( $p$-hydroxy-cinnamoylferuloy methane), and bisdemethoxycurcumin (bi $p$ hydroxy-cinnamoylmethane). The strong coloring pigment in turmeric contain curcumin, 1,7-bis(4-hydroxy-3-methoxyphynyl)1,6-heptadiene-3,5-dione, and two other cur- cuminiods (Stankovic, 2004). Sappan wood has been found to be a source of flavonoids such as 7-hydroxy-3-(4'-hydroxy benzylidene)chroman-4-one, 8-methoxybouducellin, quercetin, rhamnetin, and ombuin and sterols such as $\beta$-sitosterol, campesterol, stigmasterol, brazilin, brazilein, protosappanin $\mathrm{E}$, and taraxerol (Oh et al., 1998). Saito et al. (1985) reported butterfly pea had pigments such as kaempferol, kaemferol 3-glucoside, kaemferol 3-rodinobioside-7-rhamnoside, quercetin, and quercetin 3-glucoside. Roselle gives a brilliant red color such as Dp 3-sambubioside $(70.9 \%$, reddish violet color). Cyanidin 3 -sambubioside $(29.1 \%)$ is also present with lesser amounts of $\mathrm{Dp}$ and $\mathrm{Cy} 3$-glucoside (Pouget et al., 1990). Black rice gives a dark purple color as a result of anthocyanin pigments such as cyaniding 3-glucoside and peonidin 3-glucoside identified by liquid chromatography-mass spectroscopy (Hu et al., 2003). Based on color and $\lambda_{\max }$ of the pigments and polyphenols detected in this study, it is possible that such compounds are 

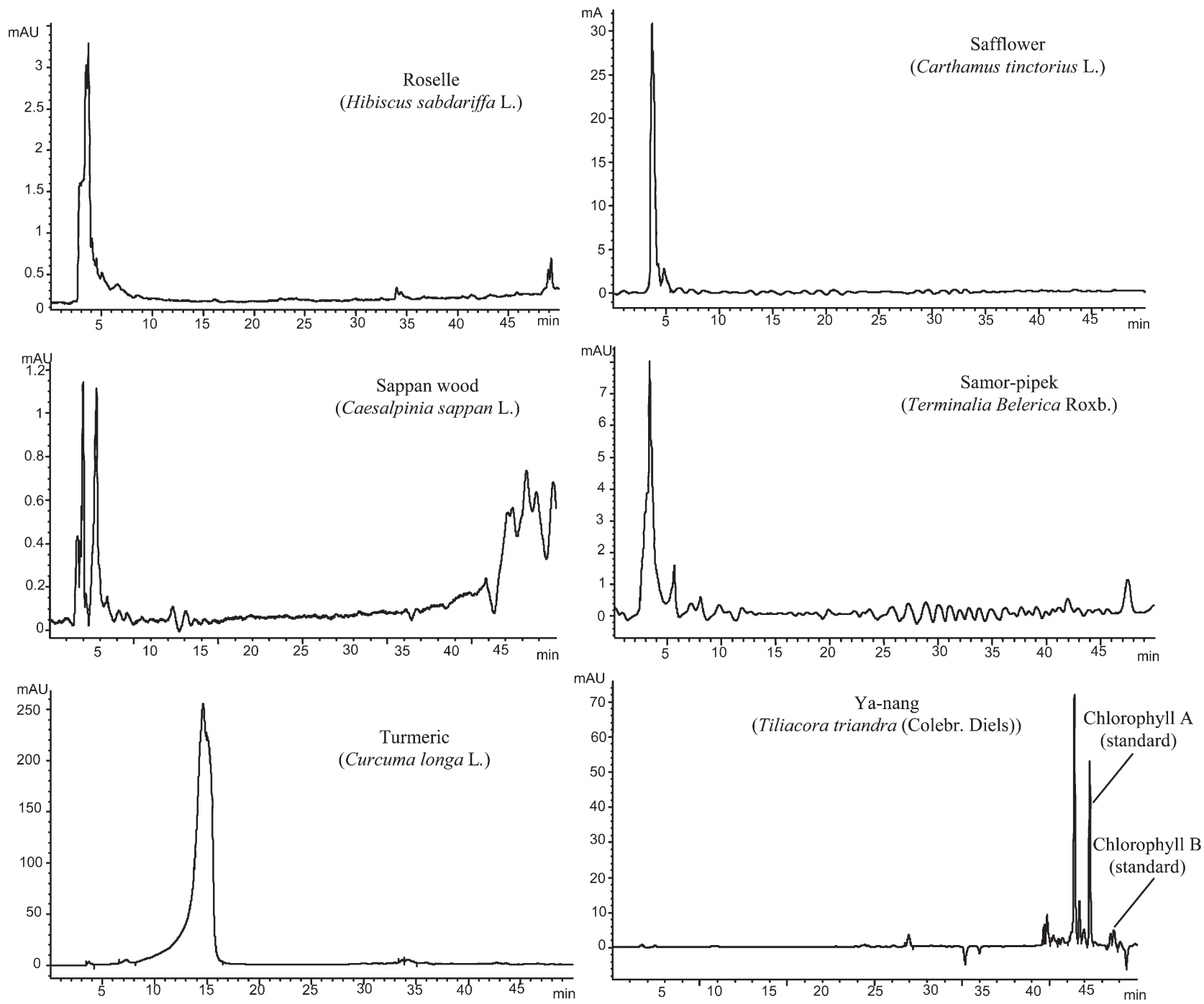

Fig. 1. (Continued)

similar and related to compounds previously identified in the literature and cited in this report.

\section{Conclusions}

Methanol extraction gave the highest yield of pigment in roselle, safflower, butterfly pea, samor-pipek, sappan wood, pradu, krachaidum, kae-lae, turmeric, and black rice. Ethanol extraction gave the highest yield of pigment in dragon fruit. Acetone extraction gave the highest yield of pigment in Ya-nang, marigold, and ebony tree. Pigments and polyphenols (colorants) of each plant extract produced a different wavelength of maximum absorption depending on the compound and concentration ratio of pigment and colorants in each plant extract. The absorption spectra of pigments and colorants in the plant extract were present in the visible region and the ultraviolet region. HPLC separation of pigments and colorants in plant extracts showed that each extract had several compounds. Ya-nang had the highest number of compounds. Pigments that can be used as coloring dyes and identified in this study are carotenoids, chlorophylls, and polyphenols such as tannins and anthocyanins. These pigments and colorants coat and penetrate hair fibers (Alpert et al., 2002). These pigments and natural colorants are widely used and are in increased demand in several industries, because the advantages of the natural dyes are harmless, non-toxic, non-carcinogenic, non-pollutant, and induce less wastewater problems. Therefore, the use of such compounds would prove to be a viable economic enterprise. Moreover, these natural colorants can be used in the textile industry, printing industry, and handicraft industry. The present study results strongly indicate that pigments and natural colorants from Thai herbal plants could have great value in cosmetic coloration and in export markets. Further studies should involve developing pigments and colorants from extracts of these Thai herbal plants for use as hair-coloring dyes in the cosmetic industry.

\section{Literature Cited}

Alpert, A., M. Altenburg, and D.C. Bailey. 2002. Milady's standard cosmetology. Delmar Thomson Learning, New York, NY.
Glimn-Lacy, J. and P.B. Kaufman. 2006. Botany illustrated: Introduction to plants, major groups, flowering plant families. Springer, New York, NY

Harnafi, H. and S. Amrani. 2008. Spectrophotometric methods for determination of plant polyphenols content and their antioxidant activity assessment: An overview. Phcog. Rev. 2:20-22.

Hecht, A. 1978. Hair dyes: A look at safety and regulation. 311-254/53. HEW Publication No. (FDA) 78-5010. U.S. Government Printing Office, Rockville, MD.

$\mathrm{Hu}, \mathrm{C}$., J. Zawistowski, W. Ling, and D.D. Kitts. 2003. Black rice (Oryza sativa L. indica) pigmented fraction suppresses both reactive oxygen species and nitric oxide in chemical and biological model systems. J. Agr. Food Chem. 51:5271-5277.

Karageorgou, P. and Y. Manetas. 2006. The importance of being red when young: Anthocyanins and the protection of young leaves of Quercus coccifera from insect herbivory and excess light. Tree Physiol. 26:613-621.

Khanavi, M., M. Hajimahmoodi, M. CheraghiNiroomand, Z. Kargar, Y. Ajani, A. Hadjiakhoondi, and M.R. Oveisi. 2009. Comparison of the antioxidant activity and total phenolic contents in some Stachys species. Afr. J. Biotechnol. 8:1143-1147.

Lazzé, M.C., R. Pizzala, M. Savio, L.A. Stivala, E. Prosperi, and L. Bianchi. 2003. Anthocyanins 
protect against DNA damage induced by tertbutyl-hydroperoxide in rat smooth muscle and hepatoma cells. Mutat. Res. 535:103-115.

Lee, J. and S.J. Schwartz. 2006. Pigments in plant foods. In: Hui, Y.H. (ed.). Handbook of food science, technology and engineering. Vol. 1. CRC-Taylor \& Francis, New York, NY.

Maisuthisakul, P., M. Suttajit, and R. Pongsawatmanit. 2005. Assessment of phenolic content and free radical-scavenging capacity of some Thai indigenous plants. Food Chem. 100:1409-1418.

Oh, S.R., D.S. Kim, I.S. Lee, K.J. Jund, J.J. Lee, and H.K. Lee. 1998. Anticomplementary activity of constituents from heartwood of Caesalpinia sappan. Planta Med. 64:456-458.

Panayotov, P., D. Stoyanov, S. Kjulanova, and M. Panayotov. 2006. Entomology to public health 2006: Determination of the quantity of flavo- noids in plant extracts by UV-spectrophotometry. Jan. 2009. <http://www.cababstractsplus.org/ abstracts/Abstract.aspx?AcNo=20013014883>.

Pouget, M.P., B. Vennat, B. Lejeune, and A. Pourrat. 1990. Extraction analysis and study of the stability of Hibiscus anthocyanins. Lebenson. Wiss. Technol. 23:103-105.

Ross, C.W. 1974. Plant physiology laboratory manual. Wadsworth Publishing Company, Inc., Belmont, CA.

Saito, N., K. Abe, T. Honda, C.F. Timberlake, and P. Bridle. 1985. Acylated delphinidin glucosides and flavonols from Clitoria ternatea. Phytochemistry 24:1583-1586.

Shahidi, F. and M. Naczk. 2003. Phenolics in food and nutraceuticals. CRC Press, Boca Raton, FL.

Solovchenko, A.E., O.B. Chivkunova, M.N. Merzlyak, and I.V. Reshetnikova. 2001. A spectrophotometric analysis of pigments in apples. Russ. J. Plant Physiol. 48:693-700.

Stankovic, I. 2004. Curcumin: Chemical and Technical Assessment (CTA): First draft in JECFA on line publication. Oct. 2008. $<\mathrm{http}: / / \mathrm{ftp} / / \mathrm{ftp}$. fao.org/es/esn/jecfa/cta_61_curcumin.pdf $>$.

Thun, M.J., S.F. Altekruse, M.M. Namboodiri, E.E. Calle, D.G. Myers, and C.W. Heath, Jr. 1994. Hair dye use and risk of fatal cancers in U.S. women. J. Natl. Cancer Inst. 86:210-215.

Tietjen, J.H. 1970. Studies on the absorption spectra of plant pigments in estuaries. Hydrobiologia 35:420-430.

Zheng, T., T.R. Holford, P.H. Mayne, P.H. Owens, P. Boyle, B. Zhang, Y.W. Zhang, and S.H. Zahm. 2002. Use of hair coloring products and breast cancer risk: A case-control study in Connecticut. Eur. J. Cancer 38:1647-1652. 